\title{
The Current Status and Development Trend of Publications Based on VR Technology
}

\author{
Yang Jinyu \\ Journal Editorial Department, Kunming University, Kunming 650214, China
}

Keywords: mobile terminals; digital media; publications; VR technology

\begin{abstract}
With the continuous growth of mobile terminals and digital media, traditional paper publications have been unable to meet the needs of the new era. This paper first analyzes the characteristics and advantages of VR technology, introduces the application status and prospects of VR technology in publications, and analyzes the problems of publications based on the VR technology based on the shortcomings of the traditional paper publications, and puts forward the policy of formulating VR publications industry standards to improve VR technology and sales channels and many other countermeasures.
\end{abstract}

\section{Introduction}

VR (Virtual Reality) technology, which is based on computer, combines network technology, image simulation, man-machine interface, pattern recognition, sensor, AI, automatic control and remote operation, and handles Abstract fuzzy information as an analog loop that is completely similar to a particular real environment in the aspects of listening, seeing, smell, and feeling. Environment, the user controls the objects in the simulated environment with the help of human-machine interaction equipment, so that users can immerse themselves in real time and feel the three-dimensional world in the simulated environment in real time.

The virtual reality system includes two parts: information input and output feedback. Input devices are data glove, game handle, keyboard, mouse, data clothing, etc. output feedback is BOOM display, helmet mounted display or LCD screen. Users use input devices and other sensors to manipulate the virtual environment directly, and get real-time 3D display and force and touch feedback. When the virtual reality system and the external world make up a closed loop control system through the sensing device, the user is also manipulating the external world in the interaction with the virtual model.

\subsection{The application of VR technology in publications}

In the Internet and digital era, traditional printing and publishing media are facing difficulties. Magazines and newspapers take various measures to win and maintain readers. The VR technique is especially suitable for books and publications, the scene, reading is very good, the introduction of reveries. VR publishing is mainly based on readers. It allows readers to explore rich learning materials independently.

For example, BizBash Media, the famous American business magazine, is the largest media company to cover the conference and activity industry, for example, to apply VR technology to books publishing. BizBash magazine was originally a printed publication. It has been changing steadily before it became a fully digital magazine in 2017. In order to reissue the publication, BizBash is planning to launch VR elements. The company plans to release two printing and digital magazines and two digital magazines in 2018. The new version will be distributed to more than 20 thousand event planners. Thousands of activity planners will receive the digital version. Many researchers believe that VR technology can be applied to children's books, learning materials, newspapers and periodicals, professional books and other publishing fields.

In China, VR technology is mainly used in books, newspapers, magazines, cards, advertisements and toys developed by children. The content of the products is very wide. Users only need to download the APP developed by publishers, and then interact with books or cards to see interactive 
VR products on the terminal. In 2016, the VR textbooks for the football plate were introduced by the human education society and Qingdao press. In 2017, the Phoenix Education Publishing House of Jiangsu withdrew from the first VR science reading for the primary science of primary science; in 2016, Realmax and Pearson's educational cooperation had developed a geometric and chemical VR textbook.

\subsection{The application prospect of VR technology in publications}

2016 is the outbreak of VR technology application, also known as the first year of VR, and VR technology has been well developed. In the publication industry, VR technology has great significance for it, including:

\subsubsection{VR technology can bring additional value to the user.}

For publications, VR is a potential market. VR technology, through the development of the Internet and software, can apply the virtual information to the real life, projecting the virtual and real things into the same picture or space, instead of only being confined to the content of the paper. For fictional readers, VR can perfectly present the magnificent imagination in the book to the readers. For non fiction fact books, VR can provide readers with additional information beyond words: voice, touch, video and so on. If VR technology adds excellent content, readers will read these extra contents repeatedly.

\subsubsection{VR technology can give users a sense of immersion.}

The sense of immersion is currently used in the science and technology marketing industry, but VR technology can really make people feel immersed when they read. As Karl Rina said, when you read VR books, you are not only reading, but you are already in the book. VR technology helps readers open up a new world, and you will really get involved. This feeling of immersion is especially attractive for children. We all want our children to fall in love with reading. But in this era of electronics, many children have been able to skillfully play various touch-screen devices such as cell phone and tablet before learning to read. I believe that combining printed paper and VR digital technology can help children to love reading.

\subsubsection{VR technology is more user-friendly.}

VR technology is not only a reason for readers to read books, but also a good way for publishers to promote books and magazines. EPSON smart glasses manager believes that VR technology has more advantages and lower development cost, which provides greater possibility for large-scale promotion. If applied properly, VR can effectively integrate various distractions in book distribution. With VR technology, advertisements, posters and entity books can be connected in series. Like a movie trailer, the book can also have a preview version, using VR technology to make a lifelike fragment and then connect all the promotional materials.

\section{The Problems of Publication Based on VR Technology}

\subsection{The technical constraints on the development of VR publications.}

VR technology has brought a lot of stimulation to book publishing, but relying on this technology alone is hard to keep consumers steady for a long time. At present, most of the VR publications with higher sales in the domestic market are mature products imported from abroad, and the independent research and development of VR publications are relatively small. If businesses develop their own VR content, re establish the data content model and system database, the cost will increase greatly, then the company's profit will be reduced. If there is no important technological innovation, can appear the "same" phenomenon, thereby reducing the value of VR technology. As far as the current user feedback is concerned, primary and secondary school students generally have a phenomenon of improving memory and enthusiasm after using VR books. But the effect is satisfactory, but the VR scene in a VR book is very limited, and the reader often has a single idea of content. Therefore, VR technology seriously restricts the development of VR 
publications, improving VR technology and designing high-quality VR books.

\subsection{The price is too high and the sales are less.}

The quality of the VR publication is 1 to 2 times higher than the regular book, but the price is much higher than the conventional one, which makes many parents stand back when they see the VR book. According to the details of Chinese household consumption expenditure in 2016, we can see that $61.4 \%$ of families spend less than 6000 on educational books, and VR books and users' families hope that the price of VR publications is below 200. Therefore, for Chinese family consumption capacity, the high price of VR publications is the main reason that restricts the development of VR publications. At the present stage, VR books, which occupy the first few seats of VR sales, are priced very well, and the sales volume is far from the regular books. In addition, the sales channels of VR books have not yet been opened up, most of them are sold on the network platform, but under the offline propaganda and promotion efforts are not enough. Therefore, after striving for price advantage, we should expand sales channels and increase sales force.

\section{The Countermeasures for the Development of Publications Based on VR Technology}

In recent years, China's VR publishing industry has made some achievements, but still faces enormous challenges and difficulties. China's VR publishing industry is still in the early stage, the scale is still relatively small, the market lacks the corresponding planning and policy, the piracy is serious, the VR book transfer rate is high. In order to solve this problem and promote the healthy development of VR publications, this paper puts forward the following countermeasures.

\subsection{The formulating the standard of VR publications industry.}

It is necessary to ensure the extensive participation of the publishing institutions and technical enterprises, to make the standard yardstick, to embody the general standard, and to integrate the new industry standards with the original other standards, not to waste the resources, and to highlight the innovation of the new line, and to pay full attention to the demand of the publishing market and the reader's experience, and to ensure the standard. The service industry and service readers reflect the applicability of the standard; strictly check the standard framework, structure, content and rules to make it conform to the relevant rules of the ISLI national standards and ensure the authority of the standard; the formulation of standards should be closely connected with the production, operation and management of the AR publications to ensure the rules of the AR publications. The safety of the standard is guaranteed.

\subsection{The formulation and release of the VR publications industry policy.}

Just like traditional book publishing needs support from printing industry, paper publishing industry also needs relevant technical support. It is suggested that the State Press and publication department, in conjunction with the Ministry of electronic industry, study the technical issues involved in electronic publications, develop technical policies and equipment policies for electronic publications, and ensure the technical and equipment support of the publishing and electronic publications.

\subsection{The improving VR technology and marketing channels.}

Based on the VR publication industry standards and policies, we should increase the research and development efforts of VR technology, expand the sales channels of VR publications, and increase sales efforts.

\section{Conclusion}

The publishing industry will be greatly changed by technology in the future. This is the future direction of publishing industry. For publishers, the use of AR augmented reality technology is the main strategy of publishing industry digitalization. As more and more people buy mobile devices 
such as mobile phones and use mobile devices to obtain more information for entertainment, the trend of digital publishing has been unstoppable. Therefore, the prospect of publication based on VR technology is very huge.

\section{References}

[1] Chen Xiang Nan. Current status and Prospect of domestic electronic publications [J]. Journal of Sichuan library science, 1999 (02): 72-77.

[2] Qin Liang Ting, Wu Yongkai. Analysis of the publication path of children's publications integrating VR technology [J]. News communication, 2018 (02): 26-27.

[3] He Guojun. The application and development strategy of VR/AR technology in digital education publishing platform [J]. China publishing, 2017 (21): 39-42.

[4] Wang Yang. Try to discuss the inevitability and feasibility of VR transformation in publishing enterprises [J]. Technology and publishing, 2017 (10): 4-8.

[5] Du Xiaoping.The application of VR technology in publishing practice[J]. Publishing wide-angle, 2017 (16): 71-73.

[6] Yan Wen Rui. The application and development of VR technology in publishing field, explore [J]. Audio-visual, 2017 (07): 238-239.

[7] Zhou Huaqing. The science popularization book VR publishing application research[J]. technology and publishing, 2017 (07): 94-97.

[8] Pan Jie. The application and limitation of VR technology in publishing [N]. China publishing media business, 2017.

[9] Wu Shuo. The philosophical thinking of virtual reality (VR) technology in the era of digital publishing[J]. Publishing wide-angle, 2017 (08): 36-38.

[10] Du Yaozong. The application status and Countermeasures of VR technology in publishing field [J]. Publishing research, 2017 (03): 36-39.

[11] Xu Lifang, Wang Yu, Chen Ming. The current development and trend of VR Education Publishing abroad [J]. Publishing reference, 2017 (03): 12-14.

[12] Yao Shun. Discussion on the application of VR technology in book publishing [J]. Modern publishing, 2016 (05): 40-41.

[13] Liu Jian, Wei Hui Yu. Digital transformation of Vocational Education Publishing Based on VR interactive platform[J]. technology and publishing, 2014 (07): 90-94.

[14] Zheng Lei. Image and language analysis of digital publications[D]. Qilu University of technology, 2012.

[15] Xu Donghui, Liu Yisong, Sun Yamin. Research and construction of VRML multi-user environment in virtual community[J]. Computer application and software, 2004 (10): 33-34, 98.

[16] Du Limin. Research on the development direction of electronic publishing under the network environment [D]. Hebei University, 2004. 